\title{
Dissemination of information and communications technology and change in school culture
}

\author{
Herminia Azinian \\ University of Buenos Aires, Miller 2377 - 8 C, Buenos Aires -1431 Argentina \\ azinian@dc.uba.ar
}

\begin{abstract}
School culture can be analysed through the relationships between people (students, teachers, and parents) and through the management of resources. This includes physical ones (like space), non-physical ones (like time), and people. In fact, each of the elements of the analysis affects the other, forming a cycle. Two schools where the principals had a strong belief in computers improving learning are analysed. The administrators and parents of these schools also felt that ICT was the core of education of future citizens. The kind of changes designed in each school, how these changes modified the school culture, and the changes that happened in the way teachers actually used ICT are compared. The main factors that seem to be responsible for the successful continuing use of ICT in one of the schools are presented.
\end{abstract}

Keywords: School culture, classroom changes, resource co-ordinator, ICT facilitator

\section{INTRODUCTION}

This paper describes a case study comparing two secondary schools in Argentina. The techniques used were interviews, observation of various aspects of support for ICT, taking notes about the observations and expanding notes through reflection and reading of the literature. When possible, descriptive data collected during the interviews were checked against data collected from direct observation.

The schools were chosen from approximately twenty public and private urban schools that the author, as a teacher educator, had visited. They were 
selected because the principals had a strong commitment to disseminate ICT in their schools. They believed that this technology should form the core of the education of future citizens. Both schools are private schools owned by parents in communities of high income families and each school has an enrollment of about 300 students.

Dissemination of ICT in Argentine schools is high as there was and still is a push to incorporate hardware. However, there is very little support for educational technology in a broad sense. Computers are placed in computer laboratories with a timetabled use for formal computing classes. Computing teachers are responsible for them because this is the easiest way to deal with the problems of managing the resources for learning and ensuring equitable access to ICT for all the students. Thus, ICT resources are more manageable, but they are isolated from the classrooms. Many teachers are unaware of what their students do while in the computer laboratories. Only a few schools are now in the process of integrating ICT resources physically into classrooms and other places.

The amount of ICT resources in schools has increased significantly during the last years. There is an important gap between the amount and the availability of ICT for educational applications. In schools with a nonsupportive environment and with the obligation to use ICT, teachers typically send students to the computer laboratory to use a word processor or to look for some information on the Web. Thus, they show a "modern" face but they only reinforce strategies that don't meet the needs of students.The school of the future is the school that prepares future "worldzens" (better than citizens) who have developed critical thinking skills with a systemic view in a context of problem solving.

\section{SCHOOL CULTURE}

When discussing the future of ICT in schools we must begin with considerations about the school itself rather than with ICT because education is the main factor of the equation. Schools have always shaped instructional uses of emerging technologies to fit with existing practices (Cuban, 1986). Those planning for an innovative school making effective use of ICT must consider the school culture. Each school is unique not only because of its own educational philosophy, expectations of the community, moral culture, political skills of its leadership, and curriculum but also because each one has its own patterns of relationships and of management of resources that determine how innovations evolve. These patterns are dynamic, depending on other conditions that will not be discussed in this paper.

The school of the future is linked to a constructivist vision of education, with students constructing their knowledge by asking questions, solving 
meaningful problems, and interacting with others in their environment. It is important to articulate this vision of the potential of ICT, although it is also possible that teachers will come to a constructivist view through using ICT in the classroom (Sandholtz, Ringstaff, \& Dwyer, 1997). Both aspects are considered when teachers deal with the power of ICT applications and also link these applications to clear curricular goals.

\section{THE CASE STUDY}

About three years ago, the schools of the case study, school 1 and school 2, appointed new principals. Both of them faced a new ICT general plan, intending that all students and teachers:

1. share a general knowledge and usage of tools so that they can take full advantage of ICT and

2. use ICT in the learning and teaching processes.

Before this time, both schools were working in the traditional way, but school 1 had been supporting teachers for curricular integration, though with scarce resources. The decision stage of the new plan in both schools included buying hardware and software and training of personnel. Compulsory courses were offered to teachers about the tools.

The set of tools selected for the first goal was similar for students of both schools (word processing, Internet, spreadsheets, graphics, presentations). It was different for teachers at school 2 (word processing, Internet, and curricular specific software) and teachers in school 1 (same tools for teachers at school 2 plus spreadsheets and presentation package).

School 1 provided courses and training in the use of the software and learning activities which demonstrated how ICT applications could be used in teaching. The teachers then had to draw upon effective models of computer integration, as recommended in Ehley (1992). Teachers were encouraged and coerced to use ICT for curricular purposes and coerced to use a computing system for grading students. After attending courses, nearly all of the teachers frequently used the Internet to find information for teaching purposes and made or let their students use the Internet.

Discussion about critical uses of Internet resources was promoted by the computer resources coordinator. Many of the teachers used content-specific applications with students (dynamic geometry, biology simulation, etc.), improving each time they used the software. A few of them haven't yet found software or an application package that adequately met their needs or their school had not yet acquired the software due to financial constraints.

Teachers in school 2 were encouraged but not coerced to use ICT for curricular purposes. They were coerced to use an internal communications system as all communications became paperless. Some of them used the 
Internet to find information for teaching purposes and made or let their students use it. Nobody used subject-specific applications.

However, teachers in both schools viewed the computer about equally as useful for instruction. The researcher felt that this statement was made to avoid conflicts in the working place, as some of the teachers showed anxiety because of school demands. As to the availability of hardware, teachers reported to have ready access to computers for themselves in both schools, but the difference was in the support they had at school 1 .

Teachers in school 1 had individual students working alone at computers, had them working in groups of two or three, took the whole class to a laboratory, or had the class working with a computer on a large screen. These options were possible because some computers were placed in the hallways and could be used there or moved to other places. There was also a computer at the sciences laboratory for specific purposes.

In school 2, computers were taken out from the laboratory and located in the hallways and in the library. It was decided not to have computing classes since "there is no need to learn, you can just use it" as the external advisor stated in his first presentation to teachers. After two years, students had timetabled computing classes again, as both the students and their parents pushed for this. Each class was distributed in three hallways, so the teacher had to go from one place to another during her lessons. This was a clear example of failure to consider school culture and community needs.

\section{TEACHERS' EXPERIENCES}

In both cases, institutional willingness to change classroom practices had been approached through inservice (but not during working hours) courses and/or workshops. Many teachers felt excited after the initial training and willing to use the new technologies. They wanted to adopt innovations but in some cases enthusiasm didn't last. This happened with the courses and workshops that lacked focus on solving educational problems, and the teachers could not transfer the skills to actual classroom implementation. Teachers with previous knowledge and experience using ICT adopted and implementated innovative practices quicker.

Teachers in both school systems have similar perceptions of what it takes to become effective users of computers for teaching and learning. They all rated courses and workshops in the school, self-training and experimentation with the computer, and encouragement and support from a facilitator as being the most important factors.

Since school 1 had a ICT resources facilitor in the staff and school 2 just an external facilitator, it is not strange that only teachers in school 1 developed implementation plans. They planned teaching materials, 
strategies, and management of change while using ICT, during in-service hours, supported by the computer coordinator and a pedagogical advisor. As experiences were successful, the use of ICT spread to other teachers.

Some innovators not only used ICT in their own classes and continued their own self-training, but also helped later adopters by becoming mentors (with no extrinsic compensation). As opportunities to come together in groups of related disciplines to share ideas and experiences were provided in the context of general changes in Argentine schools, ICT-based innovations were discussed. These meetings promoted reflection and encouraged others to attempt new projects. Teachers noted a shift from teaching to learning and a strong appreciation of their efforts by the students. As the three phases of change (adoption, implementation, and continuation) co-existed and demand of support increased, a computing assistant was also employed at school 1.

\section{THE ROLE OF THE FACILITATOR}

Each school had a designated ICT facilitator. In school 1 the facilitator (resource co-ordinator) was a person internal in the school while in the other school the facilitator was an external person who made regular visits to the school. The facilitators main tasks about ICT in education were:

1. helping teachers plan for the use of ICT, for the elaboration of educational goals, and for the development of projects to reach those goals;

2. assisting teachers in the classroom implementation of projects;

3. assessing the effects of ICT in the school, based on the quality of the integration of ICT resources in terms of students learning and the process of applying it.

In school 1 the facilitator's plan for integrating ICT considered the school's interpersonal culture, the history of successes and problems with ICT, and the configurations that offered promise of desired change. It provided a process for educating teachers and students in the use of a common set of tools, thus considering ICT education as well. The teachers had personal contact with the facilitator/coordinator and got individualized support. The facilitator spent plenty of time walking around, being where she was needed or where she could gather and give information about technical and policy issues.

Thus, in school 1, each teacher's level of knowledge about ICT, attitude toward ICT, and pedagogical practices were highly respected. Besides, the coordinator was a liaison between teachers, and facilitated teacher interchange. This was not the case in school 2. There external facilitation failed because the outside facilitator ignored the issues mentioned before. The needs of the school and of the teachers were not met. 


\section{MAJOR SUCCESS FACTORS}

The researcher found that the principal's attitude towards ICT was the main factor that started the process in each school, endorsed by the community vision. The planning and the support of a facilitator was seen as indispensable by teachers. Last, but not least, some organisational factors were seen as obstacles to cope with. These included timetabling arrangements, the disposition of the school building, and the physical distribution of resources.

\section{CONCLUSIONS}

Both schools have allocated a great amount of internal funds to their plans to become "schools of the future." Real success with ICT ultimately comes at the level of proper individual planning and use.

The components that seemed to be responsible for the successful ICTbased change in school 1 were:

1. The development of a common technological culture;

2. A supportive computer resources coordinator guiding and developing the general plan, and at the same time involved in the curriculum of the classroom;

3. Courses and workshops given in a stimulating atmosphere which supported learning to use tools, reviewing programs, and making connections with appropriate curriculum goals;

4. Content modules on specific topics given to enable teachers to develop greater expertise in areas in which they wished to specialize;

5. Post-training meetings to help the participants make plans to generalize and integrate what they had learned;

6. Individual curricular support; and

7. Organisational support.

As an educator and a policy-maker, the computer resources coordinator's role made a significant difference in the school change with her technical expertise and her understanding of the classroom into the context of the school curriculum. The experience in these schools is published in order to promote factors of change. Since teachers in the schools of the future must be knowledgeable, there is a need to promote professional groups with teachers from different schools to determine not only how ICT can be integrated in the existing curriculum, but also how it can help shape specific curricula and help teachers support each other in implementing the curricula using ICT. 


\section{REFERENCES}

Cuban, L. (1986) Teachers and Machines: The Classroom Use of Technology Since 1920. Teachers College Press, New York.

Ehley, L. (1992) Building a vision for teacher technology in education. ERIC Document Reproduction Service, No. ED 350278.

Sandholtz, J., Ringstaff, C. and Dwyer, D. (1997) Teaching with Technology: Creating Student-Centered Classrooms. Teachers College Press, New York.

\section{BIOGRAPHY}

Herminia Azinian is a professor of ICT in Education at the Sciences Teachers College of the University of Buenos Aires. She has taught at all levels, from primary and secondary schools to university and in-service teacher training. She is an advisor to schools and the author of three books and many articles. She has worked internationally for the American States Organisation and is a member of IFIP Working Group 3.1. 